\title{
Atuação do Departamento de Recursos Humanos no desempenho do setor financeiro - uma nova percepção
}

\section{Role of the Department of Human Resources in the performance of the financial sector - a new insight}

Artigo

Original

\author{
Fernanda Augusta de Oliveira Melo ${ }^{1}$ \\ Patrícia Nunes Costa Reis ${ }^{2}$ \\ Danielle Valente Pereira ${ }^{3}$ \\ Karina Rodrigues Ferreira ${ }^{3}$
}

Original

Paper

\section{Palavras-chave:}

Recursos humanos

Setor financeiro

Múltiplos papéis do $\mathrm{RH}$

\begin{abstract}
Resumo:
As profundas mudanças nos contextos financeiros, mercadológicos e tecnológicos têm resultado na necessidade de a área de Recursos Humanos (RH) reafirmar seu papel, implicando nova ética no trabalho e demandando uma visão estratégica e global de gestão de negócio e de pessoas. Entrando nesse cenário corporativo, finanças e RH reforçaram-se em suas atuações complementares, passaram a ser estratégicas e inovadoras. Diante do exposto, este trabalho teve como objetivo caracterizar as novas perspectivas de atuação do departamento de RH com o setor financeiro. Metodologicamente, este artigo consiste basicamente na utilização de pesquisa exploratória, que se apoia em revisão, análises documentais e bibliográficas, buscando sistematizar o assunto desenvolvido por outros autores de forma a atingir os objetivos propostos. Pode-se concluir que pensar em $\mathrm{RH}$ na empresa moderna e do futuro, significa entender que obter excelência empresarial deve ser um trabalho realizado com e por meio das pessoas; significa realizar a gestão com a participação efetiva dos gestores de linha, da área de RH e dos empregados de nível técnico-operacional.
\end{abstract}

Recebido em 09/2011

Aprovado em 03/2012

\section{Abstract}

The profound changes in financial contexts, market and technological advances have resulted in the need for Human Resources (HR) to reaffirm its role, implying a new work ethic, and demanding a strategic vision and overall management business and people. In this new context, among its major challenges, HR is faced with the task to monitor and interfere in the formulation of business strategies of the company. Into this scenario corporate finance and human resources have been strengthened in their complementary performances, have become strategic and innovative. Demand has expanded the focus of HR management, which must continue to account for the operational activities, but now also takes a leading role in bringing the organization to attract, develop and retain people to the strategic business organization. Given the above, this study aimed to characterize the new prospects of action of the HR department with the financial sector. Methodologically, this article is basically the use of exploratory research, which is based on that review, desk studies and literature, seeking to systematize the subject developed by other authors to achieve those goals. It can be concluded that thinking in the modern enterprise HR and the future means understanding that business excellence should be getting a work done with and through people; means to perform the management with the effective participation of line managers, the HR and employees' technical and operational level.
Key words:

\section{Human Resources}

Financial sector

Multiple roles of $R H$. 


\section{Introdução}

A globalização e a crescente competitividade têm gerado profundas mudanças nos contextos financeiros, mercadológicos e tecnológicos, exigindo um novo posicionamento do setor de Recursos Humanos (RH), em função da necessidade das empresas de incrementar a sua capacidade competitiva para enfrentar a concorrência dos mercados globalizados.

No passado, o setor de RH tinha a função burocrática, em que legalizavam, fiscalizavam e disciplinavam, hoje, é considerada uma das fontes de competitividade no cenário empresarial, demandando uma visão estratégica e global de gestão do negócio e das pessoas, objetivando proporcionar resultados sólidos e visíveis.

Nesse novo contexto, entre seus grandes desafios, o RH depara-se com a missão de acompanhar e interferir na formulação das estratégias de negócios da empresa. Demanda-se uma ampliação do foco da gestão de RH, que deve continuar a responder por atividades de âmbito operacional, mas passa também a assumir um papel de protagonista na tarefa de levar a organização a atrair, desenvolver e reter as pessoas estratégicas ao negócio da organização.

Para fazer frente a esse papel ampliado, Ulrich (2000) argumenta que o RH deve exercer múltiplos papéis: (1) Administração de Estratégias de Recursos Humanos; (2) Administração da Transformação e Mudança; (3) Administração da Infraestrutura da Empresa; e (4) Administração da Contribuição dos Funcionários. Para o exercício desses múltiplos papéis, o RH deve compartilhar responsabilidades com os Gerentes de Linha da empresa. O mesmo autor ressalta, ainda, a importância do alinhamento destes atores e assinala que a análise dos resultados da pesquisa dos múltiplos papéis de $\mathrm{RH}$,aplicada aos dois públicos (gerentes de RH e gestores de linha), pode contribuir, em diversos sentidos, para um melhor entendimento da função de $\mathrm{RH}$ e das expectativas da empresa.

Diante do exposto, este trabalho teve como objetivo caracterizar as novas perspectivas de atuação do setor de RH em consonância com o setor financeiro. Para isso, adotou-se como referencial teórico o Modelo dos
Múltiplos Papéis de Dave Ulrich, enfocando o papel chamado de "Parceiro Estratégico".

Para alcançar o objetivo proposto, realizou-se uma pesquisa básica, do tipo exploratório, utilizando, como procedimento, a revisão bibliográfica em que a abordagem do tema foi qualitativa, verificando a relação dinâmica entre o mundo real e o sujeito.

\section{Evolução Conceitual de Recursos Humanos}

A discussão teórica que suportou o presente estudo abordou quatro temas principais: a primeira, a evolução conceitual de RH- que envolve tanto as alterações no foco gerencial quanto à caracterização do papel desempenhado pela área na organização de recursos humanos- foco de análise da pesquisa; o segundo, a evolução conceitual de finanças- em que encontra como desafio mais recente o fim da era industrial e o surgimento de uma era de informação e conhecimento; o terceiro, a administração de RH dentro do contexto das mudanças- que descreve a necessidade de direcionamento estratégico e a importância das pessoas como fonte de vantagem competitiva; e, por fim, os múltiplos papéis do RH, enfocando, principalmente, no papel chamado "parceiro estratégico", em que converte a estratégia em ação.

Aquele mundo econômico cujas principais fontes de riqueza eram físicas, hoje, na era da informação, a riqueza é o produto do conhecimento. $\mathrm{O}$ capital intelectual tornou-se a matéria-prima básica e o produto mais importante da nova economia.

Para Werther Jr. e Davis (1983), o objetivo da Administração de Recursos Humanos é prover as organizações com uma força efetiva de trabalho.

Em uma época de constantes mudanças e acirrada competitividade no mundo empresarial, exige-se excelência organizacional, não só como condição de sucesso, mas também, como meio de sobrevivência, requerendo-se, consequentemente, atribuir novas funções ao RH. Analisar os acontecimentos históricos que marcaram a evolução funcional do RH, é complexo devido aos inúmeros movimentos que apresentaram características diversas e diferentes desempenhos. França (2009) estruturou essa evolução funcional do RH, conforme pode ser observado no Quadro 1, adaptado para os dias atuais. 
Quadro 1: Evolução do RH: do modelo industrial ao modelo de alta flexibilidade.

Fonte: França (2009).

\begin{tabular}{|c|c|c|}
\hline Período & Paradigmas & Características \\
\hline Anterior à 1930 & Pré-jurídico-trabalhista & $\begin{array}{l}\text { Inexistência de legislação trabalhista e de } \\
\text { departamento pessoal; } \\
\text { Descentralização das funções. }\end{array}$ \\
\hline De 1930 a 1950 & Burocrática & $\begin{array}{l}\text { Advento da legislação trabalhista; } \\
\text { Surgimento do departamento de pessoal para } \\
\text { atender às exigências legais. }\end{array}$ \\
\hline De 1950 e 1960 & Tecnicista & $\begin{array}{l}\text { Implantação da indústria automobilística; } \\
\text { Implementação dos subsistemas de RH; } \\
\text { Preocupação com eficiência e desempenho. }\end{array}$ \\
\hline De 1960 a 1980 & Sistêmica & $\begin{array}{l}\text { Surgimento da gerência do RH e do responsável } \\
\text { de relações industriais; } \\
\text { Integração dos enfoques administrativo, } \\
\text { estruturalista e comportamental. }\end{array}$ \\
\hline De 1980 e 1990 & Envolvimento & $\begin{array}{l}\text { Reformas estruturais profundas; } \\
\text { Migração do RH para as áreas operacionais; } \\
\text { Surgimento do movimento da qualidade; } \\
\text { Heterogeneidade }\end{array}$ \\
\hline Dias atuais & Alta flexibilidade & $\begin{array}{l}\text { Surgimento da reengenharia; } \\
\text { Surgimento de modelos mais radicais com maior } \\
\text { frequência; } \\
\text { Equipes flexíveis; } \\
\text { Reformulações gerais em atividades como seleção, } \\
\text { recompensa, treinamento e comunicação. }\end{array}$ \\
\hline
\end{tabular}

De acordo com o Quadro 1, é notória a transformação do Departamento Pessoal (DP) em Recursos Humanos (RH); o profissional de DP passa a ter um papel essencial nas empresas que passam a administrar o RH como estratégico. Independente do porte da empresa e do papel do RH, o DP ainda possui papel de fundamental importância, pois, continua sendo o "RH", em que o profissional de DP está inserido. Os processos para obter um departamento pessoal competitivo, com a pretensão de não ser apenas um "centro de custo", e sim, um "centro de resultados", é que o DP não deve limitar-se a efetuar atividades burocráticas, tais como: cadastros admissionais, pagamento mensal dos empregados e encargos, férias anuais, cálculos demissionais e homologação do então ex-funcionário.
Os profissionais do DP devem preparar-se para exercer orientações quanto ao correto cumprimento da legislação vigente, acompanhando o seu cumprimento, reduzindo a exposição da empresa às perdas financeiras decorrentes de eventuais fiscalizações do Ministério do Trabalho e/ou reclamações trabalhistas. Portanto, o DP, bem preparado e com profissionais capacitados a desempenhar tais atividades, torna-se um diferencial competitivo da área de RH no contexto organizacional.

\section{Setor financeiro}

Gitman (2010, p. 3) define finanças como a arte e a ciência de administrar o dinheiro. $\mathrm{O}$ setor financeiro se preocupa com as institui- 
ções, processos e as transferências de dinheiro entre o indivíduo, empresas e órgãos governamentais. Muitas pessoas se beneficiam ao entender esse termo, pois podem tomar mais decisões financeiras pessoais.

O setor financeiro vem descrevendo, ao longo do tempo, uma evolução conceitual e técnica, se ajustando aos diversos momentos da economia e encontra como desafio mais recente o fim da era industrial e o surgimento de uma era de informação e conhecimento.

Segundo Assaf Neto et al. (2009), o setor financeiro teve evolução conforme demonstrado no Quadro 2.

\section{Quadro 2 : Evolução do Setor Financeiro.}

Fonte: Elaborado pelo autor

\begin{tabular}{|c|c|c|}
\hline Período & Paradigmas & Características \\
\hline 1920 & $\begin{array}{l}\text { Revolução } \\
\text { Industrial e Fusões } \\
\text { nas Empresas }\end{array}$ & $\begin{array}{l}\text { Implementação das linhas de comercialização, com gran- } \\
\text { des margens de lucros com preços flutuantes e pouca abun- } \\
\text { dância nos recursos, reforçando a importância estrutural } \\
\text { do setor financeiro nas organizações; }\end{array}$ \\
\hline 1930 & $\begin{array}{l}\text { Recuo da Atividade } \\
\text { Econômica }\end{array}$ & $\begin{array}{l}\text { Recuo na atividade econômica em virtude da crise de } \\
\text { 1929/1930, destacando-se os estudos sobre liquidez, solu- } \\
\text { ção e a recuperação financeira da empresa; }\end{array}$ \\
\hline 1940 & $\begin{array}{l}\text { Segunda Guerra } \\
\text { Mundial }\end{array}$ & $\begin{array}{l}\text { Atribuição de maior relevância à aquisição de recursos } \\
\text { para financiar a produção de bens; }\end{array}$ \\
\hline 1950 & Período pós-guerra & $\begin{array}{l}\text { Expansão econômica mundial com eminência de uma re- } \\
\text { cessão neste período; }\end{array}$ \\
\hline 1960 & $\begin{array}{c}\text { Redução nos lucros } \\
\text { das empresas con- } \\
\text { solidadas e elevado } \\
\text { preço das ações }\end{array}$ & $\begin{array}{l}\text { Estudos de custo de capital das organizações tradicionais } \\
\text { ganham importância mais destacada. Smith (1984 apud } \\
\text { ASSAF NETO, 2009, p. 6), argumenta que somente após } \\
\text { a década de } 50 \text { é que se verificou uma mudança no estudo } \\
\text { da função financeira. }\end{array}$ \\
\hline
\end{tabular}

Evidenciou-se à época a Teoria de Eficiência dos Mercados

1970 Recessão Mundial ganhou relevância, sendo essa uma das mais importantes contribuições à Teoria de Finanças desenvolvida nesse período;

\begin{tabular}{|c|c|c|}
\hline 1980 & $\begin{array}{c}\text { Planejamento } \\
\text { Estratégico }\end{array}$ & $\begin{array}{l}\text { Provocou elevada revolução corporativa, pois levou as em- } \\
\text { presas a pensarem em sua gestão de forma global, onde } \\
\text { todos os setores se faziam presentes para discutir, avaliar } \\
\text { e traça objetivos estratégicos. Uma prática de gestão que } \\
\text { sabiamente se encontra vigente até hoje. }\end{array}$ \\
\hline 1990 & $\begin{array}{l}\text { Governança } \\
\text { Corporativa }\end{array}$ & $\begin{array}{l}\text { RH passou a ter estratégias inovadoras. Com a mudança } \\
\text { cultural de gestão os departamentos das empresas passa- } \\
\text { ram a ser células integradas em torno de uma única mis- } \\
\text { são. Constatou-se uma parceria entre finanças e RH, como } \\
\text { planos de ação, otimizando meios para alcançar resultados } \\
\text { comuns. }\end{array}$ \\
\hline
\end{tabular}


Diante do exposto no Quadro 2, o administrador financeiro de hoje está mais envolvido com o desenvolvimento e a implementação de estratégias empresariais que, por objetivo, têm o crescimento da empresa e a melhoria de sua posição competitiva no mercado.

\section{Estratégia Competitiva}

Verifica-se que a área de RH é muito sensível às mudanças que ocorrem no ambiente. Somente pelo fato de as pessoas, hoje, serem fundamentais na busca de vantagem competitiva e na criação de valor, já leva a uma concepção de estratégica competitiva de RH.

Costa (2007, p.388), conceitua estratégias competitivas como sendo o que a empresa ou entidade decide fazer em cada área estratégica, considerando-se as oportunidades e ameaças especificas, os fatores-chave de escolha, a potencialidade daquele mercado e a posição estratégica assumida por seus concorrentes diretos. Já o conceito de estratégias corporativas é o que a empresa ou entidade opta fazer, em grandes linhas, considerando-se as tendências, as oportunidades e as ameaças, os catalisadores e os ofensores do ambiente externo, bem como os pontos fortes, os pontos fracos e os pontos a melhorar, identificados na empresa ou entidade.

Menezes (2009) complementa que, para uma empresa obter sucesso e se manter competitiva, é necessário criar estratégias que possibilitem uma melhor adequação às exigências do mercado, com isso, um dos exemplos de como a atuação do setor de Recursos Humanos favorece a essa criação de táticas, é a elaboração de uma estratégia organizacional que torna-se um fator indispensável. [...] a vantagem de elaborar um planejamento estratégico em RH é que através dessa ação a empresa poderá garantir o alinhamento das ações voltadas para a Gestão de Talentos com a estratégia e o negócio da organização, consequentemente, com o alcance dos resultados.

Portanto, o RH deve se livrar dos paradigmas impostos, nos quais se acomodou ao longo dos anos, e assumir de vez sua importância e responsabilidade, em cuidar do desenvolvimento da organização, assumindo assim, seu papel fundamental de parceiro empresarial que alinha as políticas e práticas de gestão de pessoas às estratégias competitivas, além de estabelecer a direção de mudanças para que possa adicionar "valor" a investidores, clientes e funcionários.

\section{Os Múltiplos Papéis do RH nas Empresas Modernas}

Analisando o novo contexto da relação entre empregadores e trabalhadores, a antiga área de RH, nos últimos anos, enfrenta uma forte transição, assumindo o papel fundamental de parceiro empresarial, alinhando as políticas e práticas de gestão de pessoas às estratégias organizacionais, além de estabelecer a direção da mudança para que possa adicionar "valor" a investidores, clientes e funcionários.

Ulrich (2002) propõe um "Modelo de Múltiplos Papéis" para a Gestão de RH, com o objetivo precípuo de criar valor e obter resultados para organização como um todo. Esse modelo descreve as metas focadas pelo $\mathrm{RH}$ e os quatro papéis fundamentais que os profissionais da área de RH devem desempenhar para ajudar a gerar e manter uma organização competitiva.

O mesmo autor ressalta que o RH deve encontrar o ponto ótimo de gerenciamento de suas atividades, de modo a balancear adequadamente seus quatro papéis principais numa organização. O setor de RH deve, ao mesmo tempo, ter foco em estratégia de longo prazo e foco operacional de curto prazo, ou seja, ter uma visão e execução estratégica de construção das bases competitivas da empresa no futuro, sem perder de vista a rotina e o cotidiano operacional que sustenta a empresa no momento presente.

Dessa forma, as atividades de RH devem englobar desde a administração de processos (ferramentas e sistemas de RH) até a administração de pessoal tradicional. Ainda sobre a égide do autor, deve-se aprofundar este modelo de atuação de RH com base nos quatro papéis definidos conforme a meta a ser cumprida, agregando em quatro metáforas, referenciadas por meio do Quadro 3. 


\begin{tabular}{|l|l|l|l|}
\hline \multicolumn{1}{|c|}{ Papel/função } & \multicolumn{1}{|c|}{ Resultado } & \multicolumn{1}{c|}{ Metáfora } & \multicolumn{1}{c|}{ Atividade } \\
\hline $\begin{array}{l}\text { Administração de } \\
\text { estratégias de RH }\end{array}$ & $\begin{array}{l}\text { Execução da } \\
\text { estratégia }\end{array}$ & $\begin{array}{l}\text { Parceiro } \\
\text { Estratégico }\end{array}$ & $\begin{array}{l}\text { Estimulação e liderança de discussões } \\
\text { sérias sobre o modo como a empresa } \\
\text { deveria ser organizada a fim de } \\
\text { desenvolver suas estratégias; }\end{array}$ \\
\hline $\begin{array}{l}\text { Administração da } \\
\text { infraestrutura }\end{array}$ & $\begin{array}{l}\text { Construção de } \\
\text { infraestrutura } \\
\text { eficiente }\end{array}$ & $\begin{array}{l}\text { Especialista } \\
\text { administrativo }\end{array}$ & $\begin{array}{l}\text { Abandonar a imagem tradicional de } \\
\text { normatizadores e fiscalizadores e, } \\
\text { assegurar que o trabalho rotineiro seja } \\
\text { executado; }\end{array}$ \\
\hline $\begin{array}{l}\text { Administração- } \\
\text { contribuição dos } \\
\text { funcionários }\end{array}$ & $\begin{array}{l}\text { Aumento do } \\
\text { desenvolvimento } \\
\text { e habilidade dos } \\
\text { colaboradores }\end{array}$ & $\begin{array}{l}\text { Defensor dos } \\
\text { funcionários }\end{array}$ & $\begin{array}{l}\text { O RH deve ser responsável orientar e } \\
\text { treinar a gerência das demais áreas sobre } \\
\text { a importância de elevar a moral dos } \\
\text { empregados e como fazê-lo; }\end{array}$ \\
\hline $\begin{array}{l}\text { Administração- } \\
\text { transformação e } \\
\text { da mudança }\end{array}$ & $\begin{array}{l}\text { Criação de } \\
\text { organização } \\
\text { renovada }\end{array}$ & $\begin{array}{l}\text { Agente da } \\
\text { mudança }\end{array}$ & $\begin{array}{l}\text { As mudanças amedrontam e levam } \\
\text { a inércia. O RH deve trabalhar para } \\
\text { substituir a resistência ou resolução, } \\
\text { planejamento por resultados, medo ou } \\
\text { entusiasmo. }\end{array}$ \\
\hline
\end{tabular}

Assim, de acordo com o Quadro 3, para ser um parceiro empresarial, deve-se exercer com habilidade e flexibilidade exigidas, de acordo com o grau de maturidade e competitividade do negócio, os quatro múltiplos papéis de RH: parceiro estratégico, especialista administrativo, defensor dos funcionários e agente de mudança.

O RH deve delegar o papel de cuidar das pessoas para os gestores de equipes. São eles que precisam aprender a cuidar de seu pessoal dentro de políticas institucionalmente definidas,

\section{Conclusão}

Concluiu-se que para obter excelência empresarial e garantir a sustentabilidade e permanência no mercado, as organizações modernas necessitam buscar sintonia entre os níveis hierárquicos: estratégico, o tático e o operacional com intuito de equilibrar os centros de decisão e otimizar as atividades, além de promover parceria entre as Finanças e os Recursos Humanos, com planos de ações complementares, otimizando meios para alcançar resultados comuns. Contudo, ainda existe um problema muito comum, mas com a sensibilidade e flexibilidade que só o líder pode aplicar. O RH então deve desempenhar o papel de consultor interno destes líderes, assessorando-os e desenvolvendo suas habilidades de comunicação, liderança e negociação.

Com isso, é esperado que o RH se libere mais para aprender sobre o negócio, contribuir com a construção e implementação das estratégias corporativas de longo prazo e aumentar a união entre competências organizacionais e pessoais.

que se refere à estrutura gerencial: a confiança no processo de gerenciamento estratégico. Há certa inflexibilidade com relação à importância da contribuição ou participação do RH nas atividades de gerenciamento estratégico das organizações. Atendendo a este cenário corporativo, finanças e RH reforçaram suas atuações complementares, como supridoras de recursos financeiros e de pessoas, integrando a rede de valor e atuando estrategicamente. Daí ressalta-se a importância da gestão estratégica de RH que pode vir a contribuir para o desempenho financeiro das organizações. 


\section{Referências Bibliográficas}

1. ASSAF N., A.; LIMA, F. G.; Curso de administração financeira. $1^{\text {a }}$ ed. São Paulo: Atlas, 2009.

2. BARROS, W. M. de. Financeiro $\mathbf{x}$ Recursos Humanos: Uma aliança lucrativa. 2008. Disponível em: www. forumsaudecorporativa.com.br. Acesso: 26/11/2010.

3. BERVIAN, P. A.; CERVO, A. L.; SILVA, $\mathrm{R}$ da. Metodologia Científica. São Paulo: Pearson Education do Brasil, 2007.

4. CHIAVENATO, I. Administração de Recursos Humanos: Fundamentos Básicos. $7^{\mathrm{a} e d . ~ S a ̃ o ~ P a u l o: ~ M a n o l e, ~} 2009$.

5. COSTA, E. A. da. Gestão Estratégica: da empresa que temos para a empresa que queremos/ Eliezer Arantes da Costa. $2^{a}$ ed. São Paulo: Saraiva, 2007.

6. FRANÇA, A. C. L. Práticas de Recursos Humanos - PRH: conceitos, ferramentas e procedimentos. $1^{\text {a }}$ ed. São Paulo: Atlas, 2009.
7. GITMAN, L. J. Princípios de Administração Financeira. 12 $2^{\mathrm{a}}$ ed. São Paulo: Pearson Prentice Hall, 2010.

8. MINAYO MC. O desafio do conhecimento: pesquisa qualitativa em saúde. Rio de Janeiro: Abrasco; 2007.

9. ULRICH, D. Os Campeões de Recursos Humanos: inovando para obter os melhores resultados. $7^{\text {a }} \quad$ Ed. São Paulo: Futura, 2002.

10. Recursos Humanos Estratégicos. São Paulo, Editora Futura, 2000.

11. WERTHER JR,. B.; DAVIS, K. Administração de Pessoal e Recursos Humanos. São Paulo: McGraw-Hill, 1983.

12. VERGARA, S. C. Projetos e relatórios de pesquisa em administração. Rio de Janeiro: Atlas. 10ª ed. 2009.
Endereço para Correspondência:

Fernanda Augusta de Oliveira Melo

fernanda.melo@foa.org.br

Centro Universitário de Volta Redonda - UniFOA

Campus Olezio Galotti

Av. Paulo Erlei Alves Abrantes, ${ }^{\circ} 1325$

Três Poços - Volta Redonda - RJ

CEP: 27240-000 